\title{
Extubation failure influences clinical and functional outcomes in patients with traumatic brain injury*
}

\author{
A falência da extubação influencia desfechos clínicos e funcionais em \\ pacientes com traumatismo cranioencefálico \\ Helena França Correia dos Reis, Mônica Lajana Oliveira Almeida, \\ Mário Ferreira da Silva, Mário de Seixas Rocha
}

\begin{abstract}
Objective: To evaluate the association between extubation failure and outcomes (clinical and functional) in patients with traumatic brain injury (TBI). Methods: A prospective cohort study involving 311 consecutive patients with TBI. The patients were divided into two groups according to extubation outcome: extubation success; and extubation failure (defined as reintubation within $48 \mathrm{~h}$ after extubation). A multivariate model was developed in order to determine whether extubation failure was an independent predictor of in-hospital mortality. Results: The mean age was $35.7 \pm 13.8$ years. Males accounted for $92.3 \%$. The incidence of extubation failure was $13.8 \%$. In-hospital mortality was $4.5 \%$ and $20.9 \%$ in successfully extubated patients and in those with extubation failure, respectively $(p=0.001)$. Tracheostomy was more common in the extubation failure group (55.8\% vs. 1.9\%; $p$ $<0.001)$. The median length of hospital stay was significantly greater in the extubation failure group than in the extubation success group ( 44 days vs. 27 days; $p=0.002$ ). Functional status at discharge was worse among the patients in the extubation failure group. The multivariate analysis showed that extubation failure was an independent predictor of in-hospital mortality $(\mathrm{OR}=4.96 ; 95 \% \mathrm{Cl}, 1.86-13.22)$. Conclusions: In patients with $\mathrm{TBl}$, extubation failure appears to lengthen hospital stays; to increase the frequency of tracheostomy and of pulmonary complications; to worsen functional outcomes; and to increase mortality.
\end{abstract}

Keywords: Brain injuries; Ventilator weaning; Intensive care units; Glasgow outcome scale.

\section{Resumo}

Objetivo: Avaliar a associação entre falência da extubação e desfechos clínicos e funcionais em pacientes com traumatismo cranioencefálico (TCE). Métodos: Coorte prospectiva com 311 pacientes consecutivos com TCE. Os pacientes foram divididos em dois grupos de acordo com o resultado da extubação: sucesso ou falência (necessidade de reintubação dentro de $48 \mathrm{~h}$ após extubação). Um modelo multivariado foi desenvolvido para verificar se a falência de extubação era um preditor independente de mortalidade hospitalar. Resultados: A média de idade foi de 35,7 $\pm 13,8$ anos, e 92,3\% dos pacientes eram do sexo masculino. A incidência de falência da extubação foi de 13,8\%. A mortalidade hospitalar foi, respectivamente, de $20,9 \%$ e $4,5 \%$ nos pacientes com falência e com sucesso da extubação $(p=0,001)$. A realização de traqueostomia foi mais frequente no grupo falência da extubação $(55,8 \%$ vs. $1,9 \% ; p<0,001)$. A mediana de tempo de permanência hospitalar foi significantemente maior nos pacientes com falência do que naqueles com sucesso da extubação (44 dias vs. 27 dias; $p=0,002$ ). Os pacientes com falência da extubação apresentaram piores desfechos funcionais na alta hospitalar. A análise multivariada mostrou que a falência da extubação foi um preditor independente para a mortalidade hospitalar (OR = 4,96; 1C95\%, 1,86-13,22). Conclusões: A falência da extubação esteve associada a maior permanência hospitalar, maior frequência de traqueostomia e de complicações pulmonares, piores desfechos funcionais e maior mortalidade em pacientes com TCE.

Descritores: Traumatismos encefálicos; Desmame do respirador; Unidades de terapia intensiva; Escala de resultado de Glasgow.

\footnotetext{
* Study carried out under the auspices of the Graduate Program in Medicine and Human Health, Bahia School of Medicine and Public Health, Salvador, Brazil.

Correspondence to: Helena França Correia dos Reis, Rua Comendador Pereira da Silva, 174, Brotas, CEP 40285-040, Salvador, BA, Brasil.

Tel. 5571 3276-8260. E-mail: lenafran@gmail.com

Financial support: None.

Submitted: 3 October 2012. Accepted, after review: 5 March 2013.
} 


\section{Introduction}

Patients with traumatic brain injury (TBI) commonly need mechanical ventilation (MV) in order to maintain ventilation, optimize oxygenation, and protect the airway; however, the use of MV is associated with adverse effects..$^{(1,2)}$

The first phase of withdrawal of MV is designated discontinuation of ventilatory support, and studies have been conducted with the objective of determining the best timing for initiation of withdrawal. When ventilatory support can be withdrawn, the decision to extubate has to be made..$^{(3-5)}$

Although most patients are successfully removed from MV, a proportion of patients experience extubation failure; that is, there is a need for reintubation within 24-72 $\mathrm{h}$ after extubation. The extubation failure rate ranges from $5 \%$ to $20 \%$ depending on the population studied. Extubation failure has been associated with prolonged ICU and hospital stays, as well as with higher rates of tracheostomy and mortality. ${ }^{(6-10)}$

This scenario seems to be more complicated in patients with neurological involvement, higher extubation failure rates having been observed in this population. ${ }^{(11)}$ Despite reports of worse outcomes in patients with extubation failure, the impact of extubation failure on the evolution of patients with TBI remains unknown and is possibly underestimated. In addition, the association between functional outcomes and extubation failure has yet to be explored. Therefore, we conducted a prospective study in a trauma referral center with the objective of determining whether extubation failure had any influence on the length of hospital stay, the length of ICU stay, in-hospital mortality, and ICU mortality, as well as on functional outcomes at hospital discharge and at ICU discharge, in patients with TBl.

\section{Methods}

This was a prospective cohort study conducted between November of 2008 and December of 2010 and involving patients with $\mathrm{TBl}$ admitted to the ICU of the Bahia State General Hospital, located in the city of Salvador, Brazil. The present study was approved by the Research Ethics Committee of the Bahia Foundation for Science Development, and patients were included in the study after their legal guardians had given written informed consent.
We included adult patients ( $\geq 18$ years of age) who had been diagnosed with TB1, who had been on MV via an endotracheal tube for at least $48 \mathrm{~h}$, and who passed the spontaneous breathing trial (SBT). We excluded patients with spinal trauma, those who subsequently died, those who underwent tracheostomy before the first extubation, and those who had unscheduled extubation.

The patients who met the inclusion criteria were observed daily until death or discharge from the ICU. For each patient included in the study, only the first extubation attempt was analyzed. Extubation outcome was classified as extubation success or extubation failure. Extubation failure was defined as reintubation within $48 \mathrm{~h}$ after extubation. ${ }^{(12)}$

All of the decisions regarding weaning, extubation, reintubation, tracheostomy, and use of noninvasive ventilation (NIV) were made by the teams of attending physicians, without the involvement of the researchers. In accordance with standard practices, the patients were considered eligible for an SBT when they showed reversal or control of the event that led to their being placed on MV, adequate gas exchange, and hemodynamic stability. The patients were extubated if they tolerated 30-120 min of spontaneous breathing on pressure support ventilation of $7 \mathrm{cmH}_{2} \mathrm{O}$ or unassisted through a T-tube.

For all of the patients who were reintubated, we collected the following data: date of reintubation; time of reintubation; and reason for reintubation. The time to reintubation was measured in hours, and the reasons for reintubation were dichotomized into airway problems (upper airway obstruction, aspiration/excess pulmonary secretions, and bronchospasm) and nonairway problems (excessive respiratory distress, reduced level of consciousness, and others).

The level of consciousness was assessed by the Glasgow Coma Scale (GCS) score. Because all of the patients had undergone orotracheal intubation and were on MV, those who gave a verbal response received a score of 1 .

We analyzed the following clinical outcomes: death in the 1CU; in-hospital death; need for tracheostomy; length of ICU stay and length of hospital stay; pulmonary complications in the ICU; and functional outcomes at ICU discharge and at hospital discharge. 
Pulmonary complications during the ICU stay were defined as follows: pneumonia, defined as new or progressive pulmonary infiltrate on chest X-rays, accompanied by at least two of the following signs: purulent tracheal secretions, body temperature $>38.3^{\circ} \mathrm{C}$, and $25 \%$ increase in baseline leukocyte count; atelectasis on chest X-rays, accompanied by acute respiratory symptoms; tracheobronchitis, defined as increased tracheobronchial secretion volume, changes in tracheobronchial secretion color, or purulent tracheobronchial secretion, accompanied by normal chest $\mathrm{X}$-ray findings; and bronchospasm, defined as wheezing with acute respiratory symptoms requiring bronchodilator use.

The Glasgow Outcome Scale (GOS) has been widely used for evaluating outcomes in patients with TBI because the GOS addresses physical, social, and cognitive sequelae. We used the extended GOS in order to determine the functional outcome after TBl. The extended GOS consists of eight categories, the scores ranging from 1 to 8 points: total recovery (8 points); good recovery (7 points); upper moderate disability (6 points); lower moderate disability (5 points); upper severe disability (4 points); lower severe disability ( 3 points); persistent vegetative state (2 points); and death (1 point). ${ }^{(13)}$ The patients were graded on the extended GOS at ICU discharge and at hospital discharge.

The extended GOS variable was dichotomized into independent (total recovery, good recovery, upper moderate disability, and lower moderate disability) and dependent (upper severe disability, lower severe disability, persistent vegetative state, and death). ${ }^{(14)}$

The patients who failed extubation were compared with those who were successfully extubated in terms of the length of ICU stay, the length of hospital stay, tracheostomy, ICU mortality, in-hospital mortality, pulmonary complications, and functional outcome.

Categorical variables were expressed as absolute and relative frequencies. Continuous variables were expressed as mean and standard deviation or as median and interquartile range (IR), when appropriate. In order to compare categorical variables, we used the chi-square test or Fisher's exact test, when appropriate. In order to establish the statistical significance of the difference between the means of the groups, we used the Student's t-test or the Mann-Whitney test, when appropriate.

A multiple logistic regression model was used in order to assess the ability of each independent variable to predict the expected outcome (in-hospital mortality). After the univariate analysis, the independent variables were included in the logistic model if they had a value of $p<$ 0.10 and remained in the model if they remained significant $(p<0.05)$. For inclusion and exclusion of variables, a manual procedure was used.

The level of significance was set at $p<0.05$. Statistical analysis of the results was performed with the Statistical Package for the Social Sciences, version 12.0 (SPSS Inc., Chicago, IL, USA).

\section{Results}

During the study period, we included 311 consecutive patients with TBI extubated for the first time. The mean age of the patients was $35.7 \pm 13.8$ years. Of the 311 patients, 287 (92.3\%) were male, and the mean GCS score was $9.7 \pm 4.4$ at admission. The most common type of accident was motorcycle accident, in $33.8 \%$, followed by various causes, in $23.5 \%$, automobile/automobile-pedestrian accident, in $18.0 \%$, assault, in $16.4 \%$, gunshot wound, in 5.8\%, and stab wound, in $2.6 \%$. Of the 311 patients, $232(74.6 \%)$ underwent surgical treatment and $79(25.4 \%)$ underwent conservative treatment. The median duration of MV was $7 \mathrm{~h}$ (IR, 5-10 h).

Extubation failure occurred in 43 patients $(13.8 \%)$. The reasons for reintubation were respiratory failure, in 18 patients (41.9\%); upper airway obstruction, in 11 (25.6\%); reduced level of consciousness, in 7 (16.3\%); excess pulmonary secretions/inability to protect the airways, in 4 (9.3\%); bronchospasm, in 1 (2.3\%); and other reasons, in $2(4.7 \%)$. The median time to reintubation was $6.0 \mathrm{~h}$ (IR, 2.0-25.5 h). Most of the patients (27 cases, 62.8\%) had extubation failure within up to $12 \mathrm{~h}$ after extubation; 4 (9.3\%) had extubation failure within 12-23 h after extubation; 4 (9.3\%) had extubation failure within 24-35 h after extubation; and 8 (18.6\%) had extubation failure within 36-48 h after extubation. Of the 311 extubated patients, 18 (5.8\%) received NIV after extubation. The need for NIV after extubation was more common in the patients who failed extubation than in those who were successfully extubated $(11.6 \%$ vs. $4.9 \%, p=0.086$ ). 
The patients who failed extubation had longer ICU and hospital stays. In addition, ICU mortality was significantly higher in the patients who failed extubation than in those who were successfully extubated. The need for tracheostomy was significantly more common in the extubation failure group than in the extubation success group (Table 1).

The results of the univariate analysis of in-hospital mortality are shown in Table 2. After adjustment for other variables, extubation failure was independently associated with in-hospital mortality (Table 3).

Regarding the evolution of the 43 patients with extubation failure, 23 underwent extubation again; of those, 6 (27.3\%) failed extubation again. A tracheostomy was performed in $24(55.8 \%)$ of the 43 patients who had failed extubation, being performed after the first extubation failure in 19 and after the second extubation failure in 5. One patient remained intubated after the first extubation failure until death. Only 1 patient was extubated for the third time and evolved successfully.

There was a statistically insignificant difference in mortality between the patients who were reintubated because of nonairway problems and those who were reintubated because of airway problems (25.9\% vs. $12.5 \% ; p=0.45)$. Among the reintubated patients, in-hospital mortality tended to be lower in those who were reintubated within up to $12 \mathrm{~h}$ after extubation (14.8\% vs. $31.3 \% ; p=0.26$ ).

Pulmonary complications occurring during the ICU stay were evaluated in 256 of the 311 patients in the cohort, being more common in the extubation failure group than in the extubation success group (65.7\% vs. $30.8 \% ; p<0.001)$.

On the basis of the extended GOS scores, the functional outcomes at ICU discharge and at hospital discharge were worse in the patients who failed extubation than in those who were successfully extubated. The patients with extubation failure had a lower mean extended

Table 1 - Comparison of morbidity and mortality between patients who were successfully extubated and those who failed extubation. ${ }^{\mathrm{a}}$

\begin{tabular}{|c|c|c|c|}
\hline \multirow[t]{2}{*}{ Variable } & Extubation success & Extubation failure & \multirow[t]{2}{*}{$\mathrm{p}$} \\
\hline & $(n=268)$ & $(n=43)$ & \\
\hline Length of ICU stay, days & $9(7-13)$ & $15(12-19)$ & $<0.001$ \\
\hline Length of ICU stay after the first extubation, days & $3.0(2.0-5.0)$ & $8.5(5.8-14.0)$ & $<0.001$ \\
\hline Length of hospital stay, days & $27.0(19.2-36.8)$ & $40.0(24.5-59.5)$ & 0.002 \\
\hline Tracheostomy ${ }^{b}$ & $5(1.9)$ & $24(55.8)$ & $<0.001$ \\
\hline ICU mortality ${ }^{\mathrm{b}}$ & $3(1.1)$ & $6(14.0)$ & $<0.001$ \\
\hline ln-hospital mortality ${ }^{\mathrm{b}}$ & $12(4.5)$ & 9 (20.9) & 0.001 \\
\hline
\end{tabular}

${ }^{a}$ Values expressed as median (interquartile range), except where otherwise indicated. ${ }^{b}$ Values expressed as $\mathrm{n}(\%)$.

Table 2 - Univariate analysis of the factors associated with mortality in patients with traumatic brain injury. ${ }^{\mathrm{a}}$

\begin{tabular}{|c|c|c|c|}
\hline Variable & Survivors & Death & $\mathrm{p}$ \\
\hline & $(n=290)$ & $(n=21)$ & \\
\hline Age, years & $35.2 \pm 13.5$ & $43.2 \pm 16.3$ & 0.012 \\
\hline Male gender ${ }^{\mathrm{b}}$ & $267(92.1)$ & 20 (95.2) & 1.00 \\
\hline GCS score at hospital admission & $9.7 \pm 3.5$ & $9.8 \pm 3.3$ & 0.91 \\
\hline GCS score on the day of extubation & $10.7 \pm 0.7$ & $10.2 \pm 0.8$ & 0.01 \\
\hline Length of ICU stay, days ${ }^{c}$ & $10.0(7.0-13.0)$ & $14.0(9.5-19.5)$ & 0.006 \\
\hline Days on MV before the 1st extubation ${ }^{c}$ & $7.0(5-10)$ & $9.0(5-10.5)$ & 0.17 \\
\hline \multicolumn{4}{|l|}{ Type of treatment $\mathrm{t}^{\mathrm{b}}$} \\
\hline Surgical & $216(74.5)$ & $16(76.2)$ & 0.86 \\
\hline Conservative & $74(25.3)$ & $5(27.8)$ & \\
\hline Use of NIV after extubation ${ }^{b}$ & $15(5.2)$ & $3(14.3)$ & 0.112 \\
\hline Extubation failure $^{\mathrm{b}}$ & $34(11.7)$ & $9(42.9)$ & 0.001 \\
\hline
\end{tabular}

GCS: Glasgow Coma Scale; MV: mechanical ventilation; and NIV: noninvasive ventilation. ${ }^{\text {} V a l u e s ~ e x p r e s s e d ~ a s ~ m e a n ~}$ $\pm \mathrm{SD}$, except where otherwise indicated. ${ }^{b}$ Values expressed as $\mathrm{n}(\%)$. 'Values expressed as median (interquartile range). 
GOS score at ICU discharge ( $3.8 \pm 2.2$ vs. $5.5 \pm$ $1.8 ; \mathrm{p}<0.001)$ and at hospital discharge (5.0 \pm 2.4 vs. $6.0 \pm 2.0 ; p=0.036)$. The proportions of dependent patients at ICU discharge and at hospital discharge were significantly higher in the extubation failure group than in the extubation success group (67.1\% vs. $33.3 \%, p<0.001$, and $43.8 \%$ vs. $24.0 \%, p=0.018$, respectively). Figure 1 shows a comparison between the extubation success group and the extubation failure group

Table 3 - Multivariate analysis of the risk factors for in-hospital mortality in patients with traumatic brain injury.

\begin{tabular}{lccc}
\hline \multicolumn{1}{c}{ Variable } & OR & $95 \% \mathrm{Cl}$ & $\mathrm{p}$ \\
\hline Age, years & 1.04 & $1.01-1.07$ & 0.019 \\
Extubation failure & 4.96 & $1.86-13.22$ & 0.001 \\
\hline
\end{tabular}

in terms of the extended GOS categories at ICU discharge and at hospital discharge.

\section{Discussion}

The present study examined the association of extubation failure with clinical and functional outcomes in patients with TB1. The patients who failed extubation had longer ICU and hospital stays, higher rates of pulmonary complications, greater need for tracheostomy, worse functional outcome, and higher mortality.

In the present study, the incidence of extubation failure in patients with $\mathrm{TB}$ l was found to be $13.8 \%$, which is consistent with the findings of a study evaluating a similar population. ${ }^{(15)}$ The reported incidence of extubation failure varies widely, ranging from $2 \%$ to $25 \% .{ }^{(16)}$ Because of

\section{(A)}

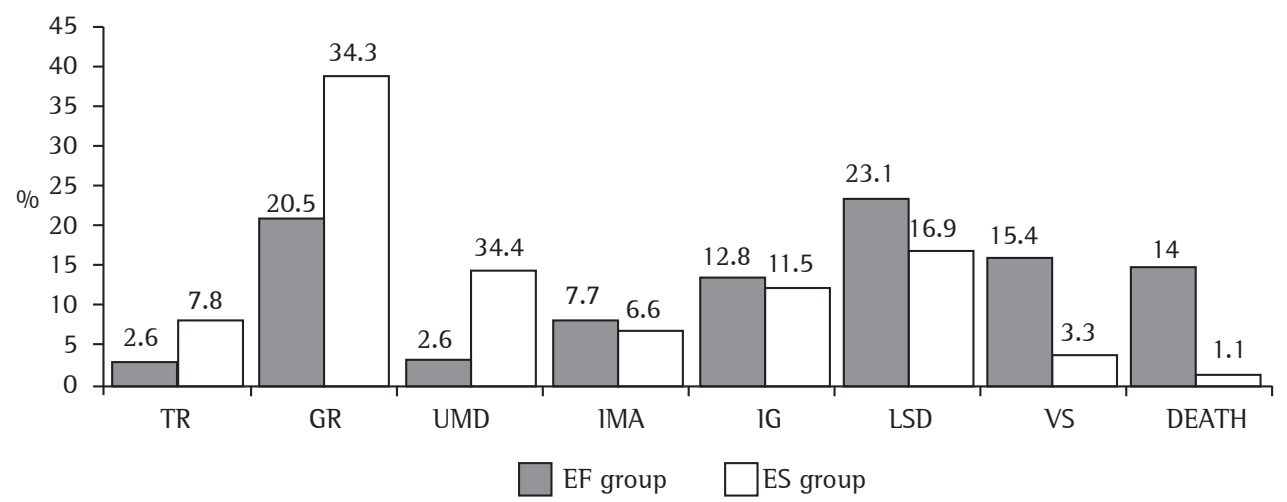

(B)

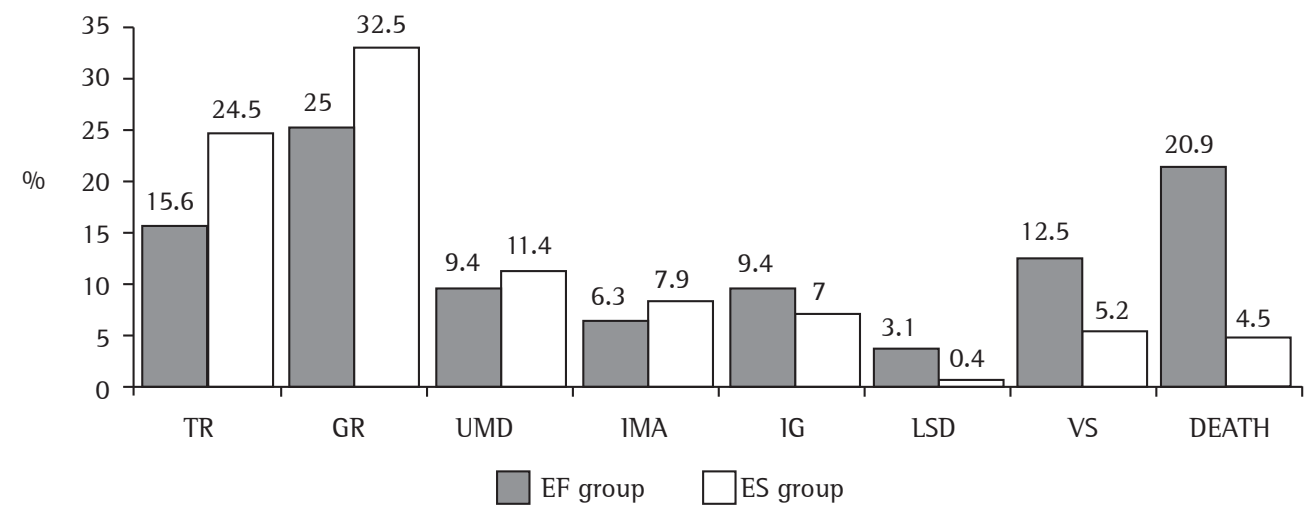

Figure 1 - Comparison of the Glasgow Outcome Scale scores at ICU discharge (in A) and at hospital discharge (B) between the patients in the extubation failure (EF) group and those in the extubation success (ES) group. TR: total recovery; GR: good recovery; UMD: upper moderate disability; LMD: lower moderate disability; USD: upper severe disability; LSD: lower severe disability; and VS: vegetative state. 
the different definitions of extubation failure across studies, it can be difficult to compare the reported incidences of extubation failure. In addition, this variation can be partially explained by the heterogeneity of the populations studied. Karanjia et al. studied a heterogeneous cohort of neurological patients and found the incidence of extubation failure to be $6 \%$, which is lower than the incidence found in the present study. This difference is due to the fact that those authors used the total number of intubated patients rather than the total number of extubated patients in order to calculate the incidence of extubation failure. ${ }^{(17)}$

Extubation failure rates have been reported to be higher in patients with neurological involvement. ${ }^{(11,18)}$ However, the reported incidence is consistent with that found in other populations..$^{(9,19)}$ A recent study suggested that the "optimal" extubation failure rate is $5-10 \% .{ }^{(20)}$ In contrast, some authors have reported that extubation failure rates of $10-15 \%$ are acceptable. ${ }^{(5)}$ It is not easy to determine the ideal extubation failure rate; however, it can be inferred that rates close to $0 \%$ indicate that many patients remained on MV for an unnecessarily long time and that extremely high rates are suggestive of premature withdrawal of MV.

The main reason for reintubation in the present study was respiratory failure, a finding that is consistent with those reported in previous studies. ${ }^{(21,22)}$ We found no association between the reason for reintubation and in-hospital mortality, a finding that corroborates those of Menon et al. ${ }^{(23)}$ In contrast with our results, the results of a study conducted by Epstein et al. ${ }^{(24)}$ showed a higher mortality in patients who were reintubated because of nonairway problems. It is plausible that, in patients who are reintubated because of upper airway obstruction, acute respiratory failure can be immediately corrected, whereas organ dysfunction cannot.

Our univariate analysis showed that the need for NIV after extubation was more common in the patients with extubation failure. It has been suggested that, when used without an appropriate selection, NIV after extubation delays the initiation of appropriate therapy and results in worse outcomes. ${ }^{(25)}$

In the present study, the patients with extubation failure had unfavorable outcomes. This finding has been reported in previous studies,
ICU mortality rates having been reported to be higher in patients who failed extubation than in those who were successfully extubated. ${ }^{(24,26)}$ In addition, we found that the patients who failed extubation had longer 1CU and hospital stays, a finding that corroborates previous findings. ${ }^{(7)}$

In our study sample, the number of patients requiring tracheostomy was substantially higher in the extubation failure group than in the extubation success group. This finding is similar to that reported by one group of authors $(66.6 \% \text { vs. } 8.6 \%)^{(10)}$ It is possible that extubation failure, when associated with other factors, such as excess pulmonary secretions and reduced level of consciousness, led to the decision of performing a tracheostomy, given that $79 \%$ of all tracheostomies were performed after the first extubation failure.

In the present study, in-hospital mortality was found to be approximately five times as high in the patients who failed extubation as it was in those who were successfully extubated, a finding that corroborates those reported in the literature. ${ }^{(21,27)}$ In addition, extubation failure was independently associated with in-hospital mortality in our sample of patients with TBI. In our multivariate analysis, age remained a risk factor for in-hospital mortality even after having been adjusted for extubation failure, a finding that is consistent with previous findings. ${ }^{(28)}$

Because of its invasive nature, reintubation is associated with increased life-threatening complications. Prolonged MV due to extubation failure can also lead to adverse outcomes. In addition, it is possible that extubation failure is only a marker of greater clinical severity. There is also the possibility that clinical deterioration occurs during the time elapsed between extubation and reintubation. ${ }^{(24)}$ One study ${ }^{(24)}$ showed that patients who were reintubated within up to 12 $\mathrm{h}$ after extubation had lower mortality than did those who were reintubated later (24\% vs. 51\%; $\mathrm{p}<0.05)$. In the present study, mortality tended to be lower in the patients who were reintubated within up to $12 \mathrm{~h}$ after extubation.

Studies have concluded that the need for reintubation increases the risk of pulmonary complications. ${ }^{(24,29)}$ A case-control study showed a higher incidence of pneumonia in patients requiring reintubation (47\% vs. $10 \%$ ). ${ }^{(29)} \mathrm{A}$ prospective study of neurological patients showed higher rates of respiratory complications in patients 
who failed extubation than in those who were successfully extubated (85\% vs. $15 \%){ }^{(8)}$ In our study, the rate of pulmonary complications was more than twice as high in the patients who failed extubation as it was in those who were successfully extubated.

Another important finding of our study was the association between extubation failure and functional outcome. The association between extubation failure and mortality or that between extubation failure and length of hospital stay has been studied..$^{(7-9,23,26)}$ However, data on the association between extubation failure and physical sequelae are scarce. Cognitive disability, prolonged $\mathrm{MV}$, and longer hospital stays are factors that might be related to a worse functional outcome in patients with $\mathrm{TBl}$ and extubation failure. In addition, critical illness polyneuropathy is one of the events that influence the decline in the functional capacity of ICU patients. One study demonstrated that critical illness polyneuropathy was an independent predictor of failure to wean from MV. ${ }^{(30)}$

The data on functionality reinforce the need for measures to prevent extubation failure, given that functional disability is related to health status and has an impact on activities of daily living. One issue to be addressed in future studies is the long-term monitoring of functional capacity in such patients.

Our study has limitations. Like any observational study, the present study is only a generator of hypotheses; however, it is reasonable to assume that the results obtained are representative of current clinical practice in the intensive care of patients with TBl. Another potential limitation is the fact that the study was conducted in a single center; nevertheless, the incidence of extubation failure was found to be within the range reported in the literature. Finally, we did not assess prognostic scores for severity. This issue was partially resolved by the inclusion of the GCS scores at admission. In addition, the impact of extubation failure on clinical outcomes was found to be consistent with that reported in previous studies. However, we recognize that future studies involving the use of prognostic scores will allow a more accurate determination of the predictive power of extubation failure for mortality in patients with TBI. Despite its limitations, the present study showed that extubation failure is a predictor of poor prognosis in patients with TBl.
In patients with $\mathrm{TB}$, extubation failure appears to lengthen hospital stays; to increase the frequency of tracheostomy and of pulmonary complications; to worsen functional outcomes; and to increase mortality.

\section{Acknowledgments}

The present study is part of the doctoral dissertation of Helena França Correia dos Reis for the Graduate Course in Medicine and Human Health, Bahia School of Medicine and Public Health, Salvador, Brazil.

\section{References}

1. Esteban A, Anzueto A, Frutos F, Alía 1, Brochard L, Stewart TE, et al. Characteristics and outcomes in adult patients receiving mechanical ventilation: a 28-day international study. JAMA. 2002;287(3):345-55. http:// dx.doi.org/10.1001/jama.287.3.345

2. PMid:117902142. Coplin WM, Pierson DJ, Cooley KD, Newell DW, Rubenfeld GD. Implications of extubation delay in brain-injured patients meeting standard weaning criteria. Am J Respir Crit Care Med. 2000;161(5):1530-6. http:// dx.doi.org/10.1164/ajrccm.161.5.9905102 PMid:10806150

3. Boles JM, Bion J, Connors A, Herridge M, Marsh B, Melot C, et al. Weaning from mechanical ventilation. Eur Respir J. 2007;29(5):1033-56. http://dx.doi. org/10.1183/09031936.00010206 PMid:17470624

4. Epstein SK. Decision to extubate. Intensive Care Med. 2002;28(5):535-46. http://dx.doi.org/10.1007/s00134002-1268-8 PMid:12029399

5. Macintyre NR, Cook DJ, Ely EW Jr, Epstein SK, Fink JB, Heffner JE, et al. Evidence-based guidelines for weaning and discontinuing ventilatory support: a collective task force facilitated by the American College of Chest Physicians; the American Association for Respiratory Care; and the American College of Critical Care Medicine. Chest. 2001;120(6 Suppl):375S-95S. http://dx.doi.org/10.1378/ chest.120.6_suppl.375S PMid:11742959

6. Epstein SK, Ciubotaru RL, Wong JB. Effect of failed extubation on the outcome of mechanical ventilation. Chest. 1997;112(1):186-92. http://dx.doi.org/10.1378/ chest.112.1.186 PMid:9228375

7. Seymour CW, Martinez A, Christie JD, Fuchs BD. The outcome of extubation failure in a community hospital intensive care unit: a cohort study. Crit Care. 2004;8(5):R322-7. http://dx.doi.org/10.1186/cc2913 http://dx.doi.org/10.1186/cc2966

8. Vidotto MC, Sogame LC, Gazzotti MR, Prandini M, Jardim JR. Implications of extubation failure and prolonged mechanical ventilation in the postoperative period following elective intracranial surgery. Braz J Med Biol Res. $2011 ; 44(12): 1291-8$. http://dx.doi.org/10.1590/ S0100-879X2011007500146 PMid:22030868

9. Frutos-Vivar F, Esteban A, Apezteguia C, González M, Arabi Y, Restrepo Ml, et al. Outcome of reintubated patients after scheduled extubation. J Crit Care. 2011;26(5):502-9. http:// dx.doi.org/10.1016/j.jcrc.2010.12.015 PMid:21376523

10. Gowardman JR, Huntington D, Whiting J. The effect of extubation failure on outcome in a multidisciplinary 
Australian intensive care unit. Crit Care Resusc. 2006;8(4):328-33. PMid:17227270

11. Vallverdú 1, Calaf N, Subirana M, Net A, Benito S, Mancebo J. Clinical characteristics, respiratory functional parameters, and outcome of a two-hour T-piece trial in patients weaning from mechanical ventilation. Am J Respir Crit Care Med. 1998;158(6):1855-62. http:// dx.doi.org/10.1164/ajrccm.158.6.9712135 PMid:9847278

12. Goldwasser R, Farias A, Freitas EE, Saddy F, Amado $\mathrm{V}$, Okamoto $\mathrm{V}$. Mechanical ventilation of weaning interruption [Article in Portuguese]. J Bras Pneumol. 2007;33 Suppl 2S:S128-36. http://dx.doi.org/10.1590/ S1806-37132007000800008 PMid:18026671

13. Jennett B, Snoek J, Bond MR, Brooks N. Disability after severe head injury: observations on the use of the Glasgow Outcome Scale. J Neurol Neurosurg Psychiatry. 1981;44(4):285-93. http://dx.doi.org/10.1136/ jnnp.44.4.285 PMid:6453957 PMCid:490949

14. Shukla D, Devi Bl, Agrawal A. Outcome measures for traumatic brain injury. Clin Neurol Neurosurg. 2011;113(6):435-41. http://dx.doi.org/10.1016/j. clineuro.2011.02.013 PMid:21440363

15. Anderson CD, Bartscher JF, Scripko PD, Biffi A, Chase D, Guanci M, et al. Neurologic examination and extubation outcome in the neurocritical care unit. Neurocrit Care. 2011;15(3):490-7. http://dx.doi.org/10.1007/s12028010-9369-7 PMid:20428967

16. Rothaar RC, Epstein SK. Extubation failure: magnitude of the problem, impact on outcomes, and prevention. Curr Opin Crit Care. 2003;9(1):59-66. http://dx.doi. org/10.1097/00075198-200302000-00011

17. Karanjia N, Nordquist D, Stevens R, Nyquist P. A clinical description of extubation failure in patients with primary brain injury. Neurocrit Care. 2011;15(1):4-12. http:// dx.doi.org/10.1007/s12028-011-9528-5 PMid:21394542

18. Namen AM, Ely EW, Tatter SB, Case LD, Lucia MA, Smith A, et al. Predictors of successful extubation in neurosurgical patients. Am J Respir Crit Care Med. 2001;163(3 Pt 1):658-64. http://dx.doi.org/10.1164/ ajrccm.163.3.2003060 PMid:11254520

19. Salam A, Tilluckdharry L, Amoateng-Adjepong Y, Manthous CA. Neurologic status, cough, secretions and extubation outcomes. Intensive Care Med. 2004;30(7):1334-9. http:// dx.doi.org/10.1007/s00134-004-2231-7 PMid:14999444

20. Krinsley JS, Reddy PK, lqbal A. What is the optimal rate of failed extubation? Crit Care. 2012;16(1):111. http://dx.doi.org/10.1186/cc11185 PMid:22356725 PMCid:3396264

21. Savi A, Teixeira C, Silva JM, Borges LG, Pereira PA, Pinto KB, et al. Weaning predictors do not predict extubation failure in simple-to-wean patients. J Crit Care. 2012;27(2):221.e1-8.

22. Teixeira C, Maccari JG, Vieira SR, Oliveira RP, Savi A, Machado AS, et al. Impact of a mechanical ventilation weaning protocol on the extubation failure rate in difficultto-wean patients. J Bras Pneumol. 2012;38(3):364-71. http://dx.doi.org/10.1590/S1806-37132012000300012 PMid:22782607

23. Menon N, Joffe AM, Deem S, Yanez ND, Grabinsky A, Dagal $\mathrm{AH}$, et al. Occurrence and complications of tracheal reintubation in critically ill adults. Respir Care. 2012;57(10):1555-63. http://dx.doi.org/10.4187/ respcare.01617 PMid:22324979

24. Epstein SK, Ciubotaru RL. Independent effects of etiology of failure and time to reintubation on outcome for patients failing extubation. Am J Respir Crit Care Med. 1998;158(2):489-93. http://dx.doi.org/10.1164/ ajrccm.158.2.9711045 PMid:9700126

25. Esteban A, Frutos-Vivar F, Ferguson ND, Arabi Y, Apezteguía C, González M, et al. Noninvasive positive-pressure ventilation for respiratory failure after extubation. $\mathrm{N}$ Engl J Med. 2004;350(24):2452-60. http://dx.doi.org/10.1056/ NEJMoa032736 PMid:15190137

26. Thille AW, Harrois A, Schortgen F, Brun-Buisson C, Brochard L. Outcomes of extubation failure in medical intensive care unit patients. Crit Care Med. 2011;39(12):2612-8. PMid:21765357

27. Saugel B, Rakette P, Hapfelmeier A, Schultheiss C, Phillip V, Thies $P$, et al. Prediction of extubation failure in medical intensive care unit patients. J Crit Care. 2012;27(6):571-7. http://dx.doi.org/10.1016/j. jcrc.2012.01.010 PMid:22440323

28. Cheng AC, Cheng KC, Chen CM, Hsing SC, Sung MY. The Outcome and Predictors of Failed Extubation in Intensive Care Patients -The Elderly is an Important Predictor. International Journal of Gerontology. 2011;5(4):206-11. http://dx.doi.org/10.1016/j.ijge.2011.09.021

29. Torres A, Gatell JM, Aznar E, el-Ebiary M, Puig de la Bellacasa J, González J, et al. Re-intubation increases the risk of nosocomial pneumonia in patients needing mechanical ventilation. Am J Respir Crit Care Med. 1995;152(1):137-41. http://dx.doi.org/10.1164/ ajrccm.152.1.7599812 PMid:7599812

30. Garnacho-Montero J, Amaya-Villar R, García-Garmendía JL, Madrazo-Osuna J, Ortiz-Leyba C. Effect of critical illness polyneuropathy on the withdrawal from mechanical ventilation and the length of stay in septic patients. Crit Care Med. 2005;33(2):349-54. http:// dx.doi.org/10.1097/01.CCM.0000153521.41848.7E PMid:15699838 


\section{About the authors}

\section{Helena França Correia dos Reis}

Adjunct Professor. Federal University of Bahia; Professor. Bahia School of Medicine and Public Health; and Physiotherapist. Bahia State General Hospital 1CU, Salvador, Brazil.

\section{Mônica Lajana Oliveira Almeida}

Supervising Physiotherapist. Bahia State General Hospital ICU; and Assistant Professor. Bahia Social School, Salvador, Brazil.

\section{Mário Ferreira da Silva}

Physiotherapist. Bahia State General Hospital ICU, Salvador, Brazil.

\section{Mário de Seixas Rocha}

Adjunct Professor. Graduate Program in Medicine and Human Health, Bahia School of Medicine and Public Health, Salvador, Brazil. 